\title{
Reversal of the Caspase-Dependent Apoptotic Cytotoxicity Pathway by Taurine from Lycium barbarum (Goji Berry) in Human Retinal Pigment Epithelial Cells: Potential Benefit in Diabetic Retinopathy
}

\author{
M. K. Song, B. D. Roufogalis, and T. H. W. Huang \\ Herbal Medicine Group, Faculty of Pharmacy, The University of Sydney, Sydney, NSW 2006, Australia \\ Correspondence should be addressed to B. D. Roufogalis, basil.roufogalis@sydney.edu.au and T. H. W. Huang, thwh@yahoo.com
}

Received 14 December 2011; Accepted 29 January 2012

Academic Editor: I-Min Liu

Copyright () 2012 M. K. Song et al. This is an open access article distributed under the Creative Commons Attribution License, which permits unrestricted use, distribution, and reproduction in any medium, provided the original work is properly cited.

\begin{abstract}
Diabetic retinopathy is a preventable microvascular diabetic complication and a leading cause of vision loss. Retinal pigment epithelial cell apoptosis is an early event in diabetic retinopathy. Taurine is reportedly beneficial for diabetic retinopathy and is abundant in the fruit of Lycium barbarum (LB). We have investigated the effect of pure taurine and an extract of LB rich in taurine on a model of diabetic retinopathy, the retinal ARPE-19 cell line exposed to high glucose. We demonstrate for the first time that LB extract and the active ligand, taurine, dose dependently enhance cell viability following high glucose treatment in the ARPE19 retinal epithelial cell line. This cytoprotective effect was associated with the attenuation of high glucose-induced apoptosis, which was shown by characteristic morphological staining and the dose-dependent decrease in the number of apoptotic cells, determined by flow cytometry. Moreover, we have shown that LB extract and taurine dose dependently downregulate caspase-3 protein expression and the enzymatic activity of caspase-3. We conclude that taurine, a major component of LB, and the LB extract, have a cytoprotective effect against glucose exposure in a human retinal epithelial cell line and may provide useful approaches to delaying diabetic retinopathy progression.
\end{abstract}

\section{Introduction}

Diabetic retinopathy (DR) is one of the most common microvascular complications of diabetes and remains a major cause of preventable blindness worldwide [1]. Diabetes damages all the major cells of the retina and pigment epithelial cells [2]. This results in increased blood flow and capillary diameter, proliferation of the extracellular matrix and thickening of basal membranes, altered cell turnover (apoptosis, proliferation), and breakdown of the blood retinal barrier [3].

Apoptosis or programmed cell death can be triggered by various signals and is characterized by well-defined morphologic changes, including chromatin condensation and fragmentation, and formation of apoptotic bodies [4]. Retinal microvascular cells are lost selectively via apoptosis before other histopathology is detectable in diabetes [5].
Moreover, recent findings have suggested that apoptotic episodes in retinal cells during the initial stage of diabetes play an integral role in the early stage of vision loss [6]. Therefore, apoptosis is important in the progression and pathogenesis of DR [7].

Retinal pigment epithelial (RPE) cells form a monolayer between the neuroretina and the choriocapillaris, which are the essential components of the outer blood retinal barrier (BRB) that maintains physiological and structural balance within the retina [8]. RPE cells are particularly susceptible to oxidative stress because of high oxygen consumption by photoreceptors [9]. Moreover, recent studies have shown that RPE cells undergo oxidative stress and UV-light induced apoptosis $[10,11]$. Although several studies have shown that RPE degenerates in the early stage of diabetes $[12,13]$, the mechanisms of high-glucose-induced apoptosis in RPE cell models of DR are not fully understood. 
High glucose causes activation of several proteins involved in apoptotic cell death, including members of the caspase family [14]. It is well known that caspases are involved in the initiation and execution of apoptosis [15]. Moreover, the widely studied caspase- 3 plays an important role in diabetes [16].

Recent studies have suggested that ligand-activated PPAR- $\gamma$ controls apoptosis, contributing to tissue protection [17]. Indeed, it has been shown that the PPAR- $\gamma$ agonist rosiglitazone protects against oxidative stress-induced apoptosis through upregulation of antiapoptotic Bcl-2 family proteins [18]. Troglitazone showed a cytoprotective activity from oxidative stress-induced apoptosis in ARPE-19 cells [19]. Moreover, the study has shown that a natural ligand, 15deoxy-delta-12,14-prostaglandin $\mathrm{J}_{2}$ (15d-PGJ 2 ), helps RPE cells to maintain mitochondrial integrity by prevention of cytochrome c (cyt c) release from mitochondria and subsequent activation of the apoptosis pathway [20].

Fruits from Lycium barbarum L. (LB) in the family Solanaceae are a well-known traditional Chinese medicine which has glucose-lowering activity and antiapoptotic activity [21]. There is a growing body of evidence indicating that LB intake increases the fasting plasma zeaxanthin levels, beneficial for maintaining macular pigment density in agerelated macular degeneration [22]. Moreover, polysaccharides of LB (LBP) increase antiapoptotic protein Bcl-2 levels in lens epithelial cells [23]. LB contains 18 types of amino acids, including taurine, a nonessential free amino acid, which is one of the chemical components most abundant in LB $[24,25]$. Taurine has been recommended as a complementary therapeutic agent for the prevention of diabetic complications in type II diabetes [26]. Moreover, it has been shown that taurine inhibits the activation of caspase3 in ischemic cardiomyocytes [27]. Taurine has also been found to prevent high-glucose-mediated endothelial cell apoptosis through its antioxidant property [28]. Recently, we have shown that $\mathrm{LB}$ extract and pure taurine, a major component in the LB extract, activated PPAR $-\gamma$ by luciferase reporter gene analysis and by mRNA and western blotting measurement in human retinal pigment epithelial cells. At the same time, both LB extract and pure taurine inhibited a variety of PPAR- $\gamma$-dependent downstream effectors in the retinal cells [29]. However, the pathways of the beneficial effect of LB and its taurine active component on DR by modulation of high-glucose-induced apoptosis through the PPAR- $\gamma$-mediated caspase- 3 pathway have not been investigated. Therefore, the aim of this study is to investigate the cytoprotective effect of pure taurine and an extract of LB rich in taurine against glucose exposure in a human retinal epithelial cell line as a model of DR.

\section{Materials and Methods}

2.1. Preparation of LB Extract. Dried LB was purchased in raw powder form (batch no. 53101: DeDu Holdings, West Ryde, Australia). The preparation of an extract of LB was performed as previously described $[29,30]$ with modifications. Briefly, $250 \mathrm{mg}$ of fine $\mathrm{LB}$ powder was extracted with $2.5 \mathrm{~mL}$ of methanol by sonication at room temperature for $15 \mathrm{~min}$ followed by centrifugation for $5 \mathrm{~min}$. This step was repeated four times. The solvent was then evaporated under reduced pressure below $50^{\circ} \mathrm{C}$, and the remaining solid was collected. The identification and quantification of taurine in the LB extract were undertaken by thin layer chromatography (TLC) analysis as previously described [29].

2.2. Tissue Culture and Treatment. The human retinal epithelial cell line, ARPE-19, was provided by Dr. Weiyong Shen (Save Sight Institute, Sydney, Australia). Cells were cultured as previously described [31]. Briefly, the cells were cultured in a humidified incubator at $37^{\circ} \mathrm{C}$ in $5 \% \mathrm{CO}_{2}$ in $10 \%$ fetal bovine serum-defined minimal essential medium (FBS-DMEM)-F12 medium) containing 5.5 mM D-glucose, supplemented with $100 \mathrm{U} / \mathrm{mL}$ penicillin $\mathrm{G}$ and $100 \mu \mathrm{g} / \mathrm{mL}$ streptomycin. The culture medium was replaced with fresh medium every second day. Upon confluence, cultures were passaged by dissociation in $0.05 \%(\mathrm{w} / \mathrm{v})$ trypsin (Gibco-Life Technologies, Roseville, MD, USA) in phosphate-buffered saline (PBS) $\mathrm{pH}$ 7.4. For high-glucose-induced functional studies, cells were maintained in fresh medium containing $1 \%$ FBS for $2 \mathrm{~h}$ prior to use in the experiments. Cells were then pretreated with samples, rosiglitazone (RG), 15deoxy-delta $(12,14)$-prostaglandin $\mathrm{J}_{2}(\mathrm{PG})$, or vehicle $(0.5 \%$ DMSO) for $6 \mathrm{~h}$ followed by further exposure to normal $(5.5 \mathrm{mM})$ or high $(33.3 \mathrm{mM}) \mathrm{D}$-glucose for $48 \mathrm{~h}$. Cells incubated in $27.5 \mathrm{mM}$ mannitol (M) served as osmotic control [32].

2.3. Cell Viability by MTS Assay. Cell proliferation was assessed by 3-(4,5-dimethylthiazol-2-yl)-5-(3-carboxymethoxy phenyl)-2-(4-sulfophenyl)-2H-tetrazolium (MTS) assay using the Cell Titer 96 Aqueous One Solution Cell Proliferation Assay Kit (Promega, Madison, WI, USA), as previously described with some modifications [33]. Briefly, ARPE-19 cells were cultured in 96 -well plates $\left(3 \times 10^{4} / \mathrm{mL}\right)$. Upon confluence, cells were treated with vehicle (0.05\% DMSO), RG, colchicine (Colch), or samples for $24 \mathrm{~h}, 48 \mathrm{~h}$, and $72 \mathrm{~h}$. For high-glucose cytotoxicity experiments, the medium was replaced with fresh medium containing $1 \%$ FBS for $2 \mathrm{~h}$ prior to use in the experiments. Cells were then preincubated with treatment samples, RG, PG, or vehicle (0.5\% DMSO) for $6 \mathrm{~h}$ followed by exposure to normal $(5.5 \mathrm{mM})$ or high $(33.3 \mathrm{mM})$ $\mathrm{D}$-glucose for a further $48 \mathrm{~h}$. On the day of the proliferation assay, $20 \mu \mathrm{L}$ of the MTS solution was added to each of the 96 wells and incubated at $37^{\circ} \mathrm{C}$ for $1 \mathrm{~h}$ in a humidified $(5 \%$ $\mathrm{CO}_{2}$ ) environment. The absorbance at $490 \mathrm{~nm}$ was read in a microplate reader (Bio-Rad Laboratories, Inc, CA). The percentage of cell proliferation was calculated as (OD of treated samples/OD of untreated control) $\times 100$.

2.4. Detection of Apoptotic Cells. Cells undergoing apoptosis were determined by Hoechst 33342 staining and Annexin V flow cytometry analysis, as previously described with modifications [4]. Briefly, cells were fixed in 4\% formaldehyde for $10 \mathrm{~min}$ and stained with Hoechst dye for $10 \mathrm{~min}$. Cells were visualized under an inverted fluorescence microscope 
(excitation at $365 \mathrm{~nm}$ and emission at $480 \mathrm{~nm}$, using a UV filter). A minimum of 300 cells in each cover slip, from six randomly selected fields, were counted, and apoptotic cells were expressed as percentage of total cells counts.

2.5. Quantification of Apoptotic Cells. Apoptotic cells were quantified by flow cytometry using FITC Annexin V apoptosis detection kit (BD Biosciences, San Jose, USA), as previously described [34]. Briefly, after appropriate treatments, 1 $\times 10^{5}$ cells $/ 100 \mu \mathrm{L}$ were collected, and $5 \mu \mathrm{L}$ of FITC Annexin $\mathrm{V}$ and $5 \mu \mathrm{L}$ of propidium iodide (PI) were added. Cells were incubated in the dark at $25^{\circ} \mathrm{C}$. After $15 \mathrm{~min}, 400 \mu \mathrm{L}$ of $1 \mathrm{x}$ binding buffer was added to the cells. The Annexin V-positive $(+) /$ PI-negative $(-)$ cells, indicating early apoptotic cells, and the Annexin V-positive (+)/PI-positive $(+)$, indicating late apoptotic cells, were detected by FACSCalibur (BD Biosciences, San Jose, USA). The results were analysed using the WINDI 2.5 software. Annexin V-FITC conjugates were detected at the FL1 channel, and PI was read on the FL3 channel.

2.6. Caspase-3 Activity Assay. Caspase-3 activity was measured by the caspase- 3 fluorometric assay system (BD Biosciences, San Jose, USA), as previously described [35] with modifications. Briefly, a total of $1 \times 10^{6}$ cells were harvested and resuspended in cold cell lysis buffer $(10 \mathrm{mM}$ Tris-HCL, $10 \mathrm{mM} \mathrm{NaH}{ }_{2} \mathrm{PO}_{4} / \mathrm{NaHPO}_{4}$ (pH7.5), $130 \mathrm{mM} \mathrm{NaCl}, 1 \%$ Triton-X-100, and $10 \mathrm{mM}$ sodium pyrophosphate (NaPPi)) for $30 \mathrm{~min}$ on ice. Cell lysate protein concentrations were determined by the BCA (bicinchoninic acid) assay (Thermo, USA) according to the manufacturer's instructions. Equal amounts of protein were added to each well in a 96-well plate containing $200 \mu \mathrm{L}$ of HEPES buffer and $5 \mu \mathrm{L}$ of the fluorogenic substrate, DEVD-AMC (7-amino-4-methylcoumarin), and incubated for $1 \mathrm{~h}$ at $37^{\circ} \mathrm{C}$. Cleavage of the substrate by active caspase- 3 resulted in an increase of fluorescence $($ excitation $=380 \mathrm{~nm}$ and emission $=460 \mathrm{~nm})$, measured in a 96-well plate fluorometer (FLUOstar OPTIMA), and expressed as unit per milligram protein.

\subsection{Protein Extraction and Semiquantitative Western Blot-} ting Analysis. Immunoblots were conducted as described previously [36]. The proteins from the cells were prepared using the Ripa lysis buffer ( $25 \mathrm{mM}$ Tris buffer ( $\mathrm{pH} 7.6)$, $150 \mathrm{mM} \mathrm{NaCl}, 1 \% \mathrm{NP}-40,1 \%$ sodium deoxycholate, and $0.1 \%$ SDS). The lysed cells were centrifuged at $12,000 \mathrm{rpm}$ (Micromax RF centrifuge, Thermo IEC, MA, USA) for $10 \mathrm{~min}$ and supernatants resolved by SDS-PAGE, 4-12\% (Invitrogen, Australia). Protein was transferred to cellulose membrane in transfer buffer (Tris base $25 \mathrm{mM}$, glycine $192 \mathrm{mM}, \mathrm{pH}$ 8.3) and blocked in 5\% skim milk powder (Sigma-Aldrich, St. Louis, MO, USA) overnight. The primary antibodies (Santa Cruz Biotechnology, USA) were anticaspase-3 rabbit polyclonal primary antibodies $(1: 500$ dilution). After incubation with the primary antibody for $1 \mathrm{hr}$ at room temperature, the membrane was washed and further incubated with horseradish peroxidase-conjugated anti-mouse secondary antibodies (1:6000 dilution; Santa
Cruz Biotechnology, USA). Bound antibodies were detected using enhanced chemiluminescence with Lumi-Light Western Blotting Substrate (Roche). The membranes were exposed to X-ray film (Kodak, USA) and developed using the SRX-101A X-ray developer (Konica, Taiwan). The resultant films were quantified by scanning densitometry using ImageJ (National Institutes of Health, Bethesda, MD). Protein expression was quantified by normalization to $\alpha$-tubulin. The membranes were reprobed with anti- $\alpha$-tubulin primary antibody (1:10,000 dilution; Santa Cruz Biotechnology, USA) after stripping and overnight blotting with 5\% skim milk. The membranes were reincubated with horseradish peroxidase-conjugated anti-mouse secondary antibody and detected using the same procedure as described above. Cell lysate protein concentrations were determined by the BCA (bicinchoninic acid) assay (Thermo, USA) according to the manufacturer's instructions.

2.8. Chemicals. Rosiglitazone (RG) was purchased from Alexis Biochemicals (San Diego, CA, USA). Pure taurine compound, 15-deoxy-delta $(12,14)$-prostaglandin $\mathrm{J}_{2}(\mathrm{PG})$, and other chemicals were purchased from Sigma-Aldrich (St. Louis, MO, USA), unless otherwise indicated.

2.9. Statistical Analysis. All results are expressed as means \pm SEM Data were analysed by 1 -factor analysis of variance (ANOVA). If a statistically significant effect was found, the Newman-Keuls test was performed to isolate the difference between the groups. $P$ values less than $0.05(P<0.05)$ were considered to indicate significance.

\section{Results}

3.1. Effect of Taurine and LB Extract on Cell Viability in ARPE19 Cells Cultured in Normal Glucose Condition. To determine whether LB extract and taurine component influenced viability in normal glucose-treated ARPE-19 cells, MTS assay was performed for $24 \mathrm{~h}, 48 \mathrm{~h}$, and $72 \mathrm{~h}$ of incubation. Incubation of LB extract at $0.001,0.01,0.1,0.5$, and $1 \mathrm{mg} / \mathrm{mL}$ in normal glucose-treated APRE-19 cells for $24 \mathrm{~h}$ and $48 \mathrm{~h}$ had little or no cytotoxicity ( $>90 \%$ viability remained). At $5 \mathrm{mg} / \mathrm{mL}, \mathrm{LB}$ extract was cytotoxic at all incubation times (Figure 1(a)).

Incubation of APRE-19 cells with taurine for $24 \mathrm{~h}, 48 \mathrm{~h}$, and $72 \mathrm{~h}$ had little or no effect on cytotoxicity ( $>90 \%$ viability remaining). At 5 and $10 \mathrm{mM}$, taurine was slightly cytotoxic (approximately $80 \%$ viability remaining) at all incubation times (Figure 1(b)).

3.2. Cytoprotective Effects of Taurine and LB Extract in ARPE19 Cells Exposed to High Glucose. As it is well established that hyperglycemia induces cell death in retinal epithelial cells [37], ARPE-19 cells were treated with $33.3 \mathrm{mM}$ glucose for $48 \mathrm{~h}$ in the presence of LB extract $(0.1,0.5$, and $0.75 \mathrm{mg} / \mathrm{mL})$ or taurine $(0.001,0.1$, and $1 \mathrm{mM})$, and their cytoprotective effect was examined by MTS assay. Since high glucose increases osmolarity, ARPE-19 cells were also exposed to an osmotic control (27.5 mM mannitol + 5.5 mM glucose). Cell 


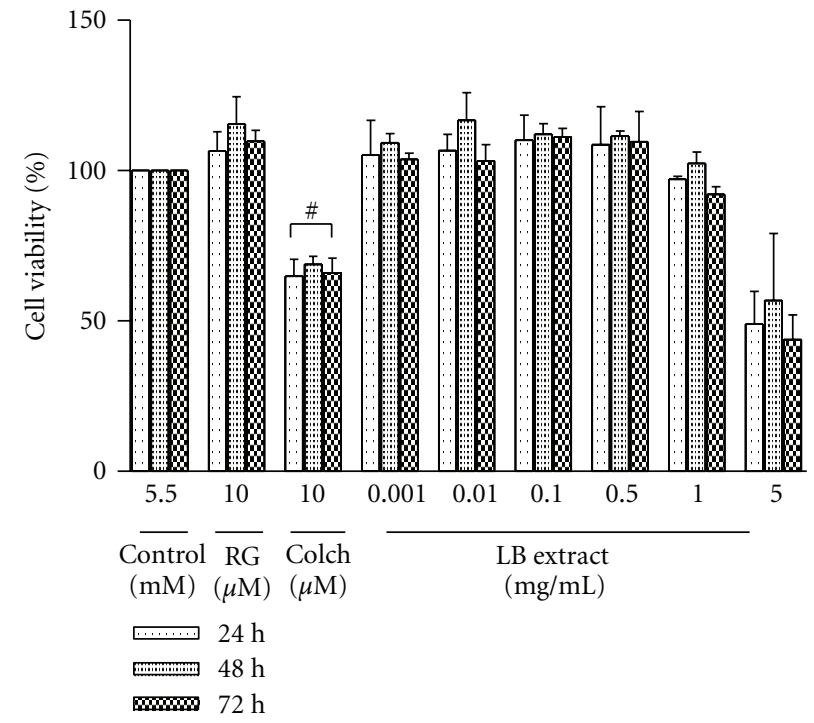

(a)

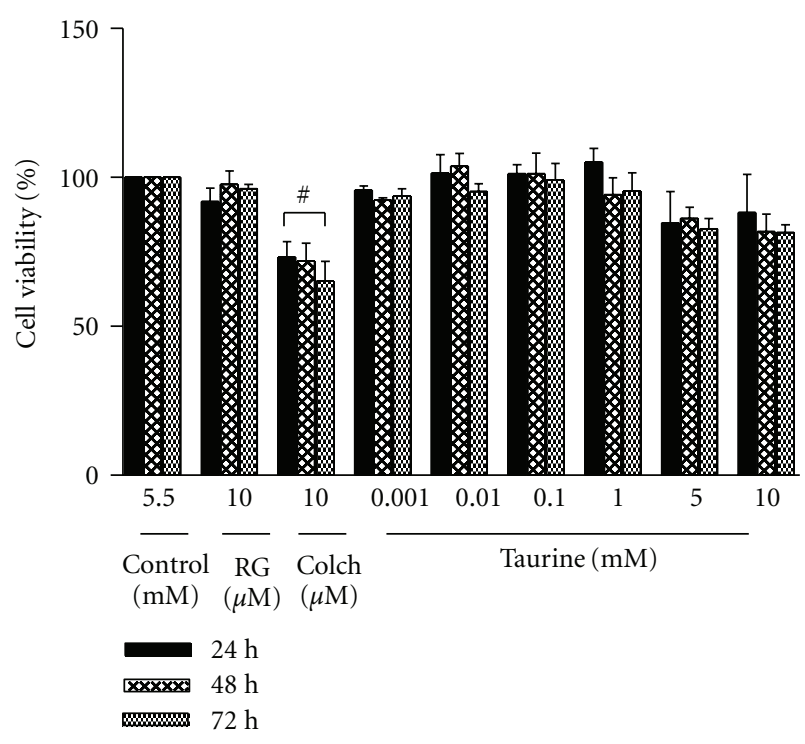

(b)

FIGURE 1: Time- and dose-dependent effect on cell viability following LB extract (a) and taurine (b) treatment. ARPE-19 cells were seeded onto 96-well plates, and LB extract $(0.001,0.01,0.1,0.5,1$, and $5 \mathrm{mg} / \mathrm{mL})$ and taurine $(0.001,0.01,0.1,5$, and $10 \mathrm{mM})$ were added to the medium for 24, 48, and $72 \mathrm{~h}$. Cell viability was measured by MTS assay. The values of cell viability were normalised to the value of the control. The data represents the mean \pm SEM of 5 independent experiments. Rosiglitazone (RG) served as positive control, and colchicine (Colch) served as negative control.

viability in $33.3 \mathrm{mM}$ glucose was significantly decreased by $59.9 \%$; the loss of viability was reversed by adding LB extract dose dependently (by 67.9, 74.4, and 81.0\%, resp.) (Figure 2). Likewise cell viability in $33.3 \mathrm{mM}$ glucose condition was reversed by adding taurine in a dose-dependent manner $(69.4,82.6$, and $89.3 \%$, resp.) (Figure 2). Loss of cell viability in high-glucose culture was similarly reversed by adding the positive controls RG (by $73.8 \%$ ) and PG (by $89.1 \%$ ). The osmotic control did not show a significant reduction in cell viability.

\subsection{Effect of Taurine and LB Extract on Cell Apoptosis in} High-Glucose-Treated ARPE-19 Cells. To investigate whether the cytoprotective effects of LB extract and taurine were due to the attenuation of high-glucose-induced apoptosis, characteristic morphological staining was performed using Hoechst 33342 and flow cytometry with Annexin V/PI double staining to identify and quantify the apoptotic cells.

Incubation with high glucose for $48 \mathrm{~h}$ induced a significant increase in the number of apoptotic cells $(26.8 \%$ of total cells), as identified by Hoechst staining, compared with normal glucose culture (Figure 3(a)). The inhibitory effect of LB extract and taurine on high-glucose-induced apoptosis was demonstrated in characteristic morphological staining (Figure $3(\mathrm{~b})$ ). Treatment with LB extract $(0.1,0.5$, and $0.75 \mathrm{mg} / \mathrm{mL}$ ) dose dependently decreased the number of apoptotic cells by $18.3,15.0$, and $8.7 \%$ of total cells, respectively, compared to the high-glucose control, reaching values comparable to those in the control cultures $(5.2 \%$ of total cells) (Figure $3(\mathrm{a}))$. Taurine $(0.001,0.1$, and $1 \mathrm{mM}$ ) dose dependently decreased the number of apoptotic cells, by

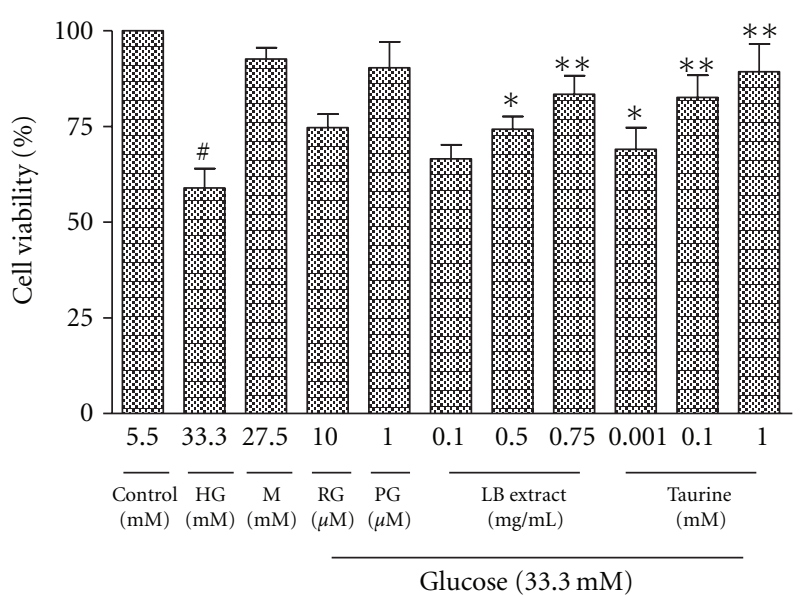

FIGURE 2: Effect of LB extract and taurine on high-glucose-induced loss of cell viability. ARPE-19 cells pretreated with LB extract $(0.1,0.5$, and $0.75 \mathrm{mg} / \mathrm{mL})$ and taurine $(0.001,0.1$, and $1 \mathrm{mM})$ were exposed to high glucose $(33.3 \mathrm{mM})$ for $48 \mathrm{~h}$. Cell viability was determined by MTS assay. Results are expressed as percentage of control and presented as mean \pm SEM $(n=6$ independent experiments). ${ }^{\#} P<0.001$ versus control; ${ }^{*} P<0.05,{ }^{* *} P<0.001$ versus high glucose (HG). Mannitol (M) served as osmotic control.

$14.0,12.0$, and $8.6 \%$ of total cells, respectively, compared to the high-glucose control, approaching values in the control cultures (5.2\% of total cells) (Figure 3(a)). The number of apoptotic cells as identified by Hoechst staining in highglucose condition was similarly decreased by the positive controls RG (9.4\%) and PG (7.6\%). 


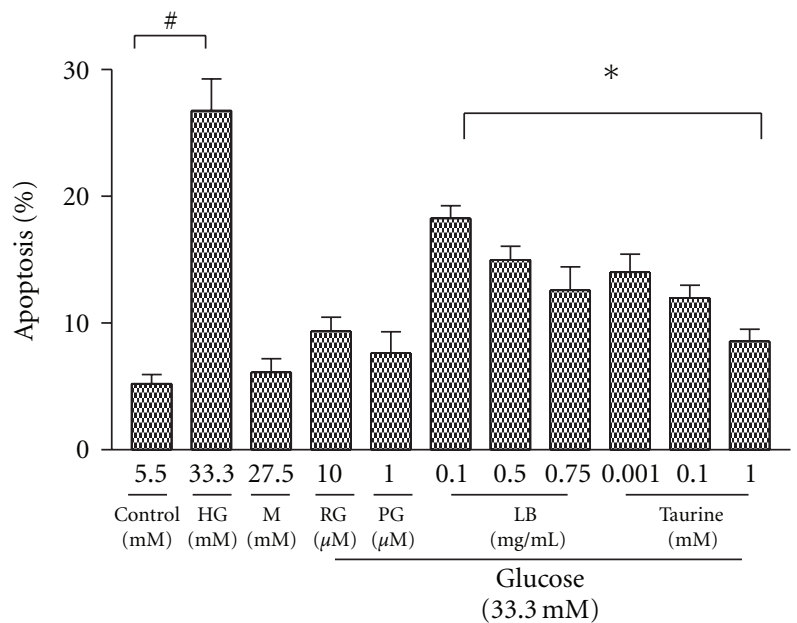

(a)
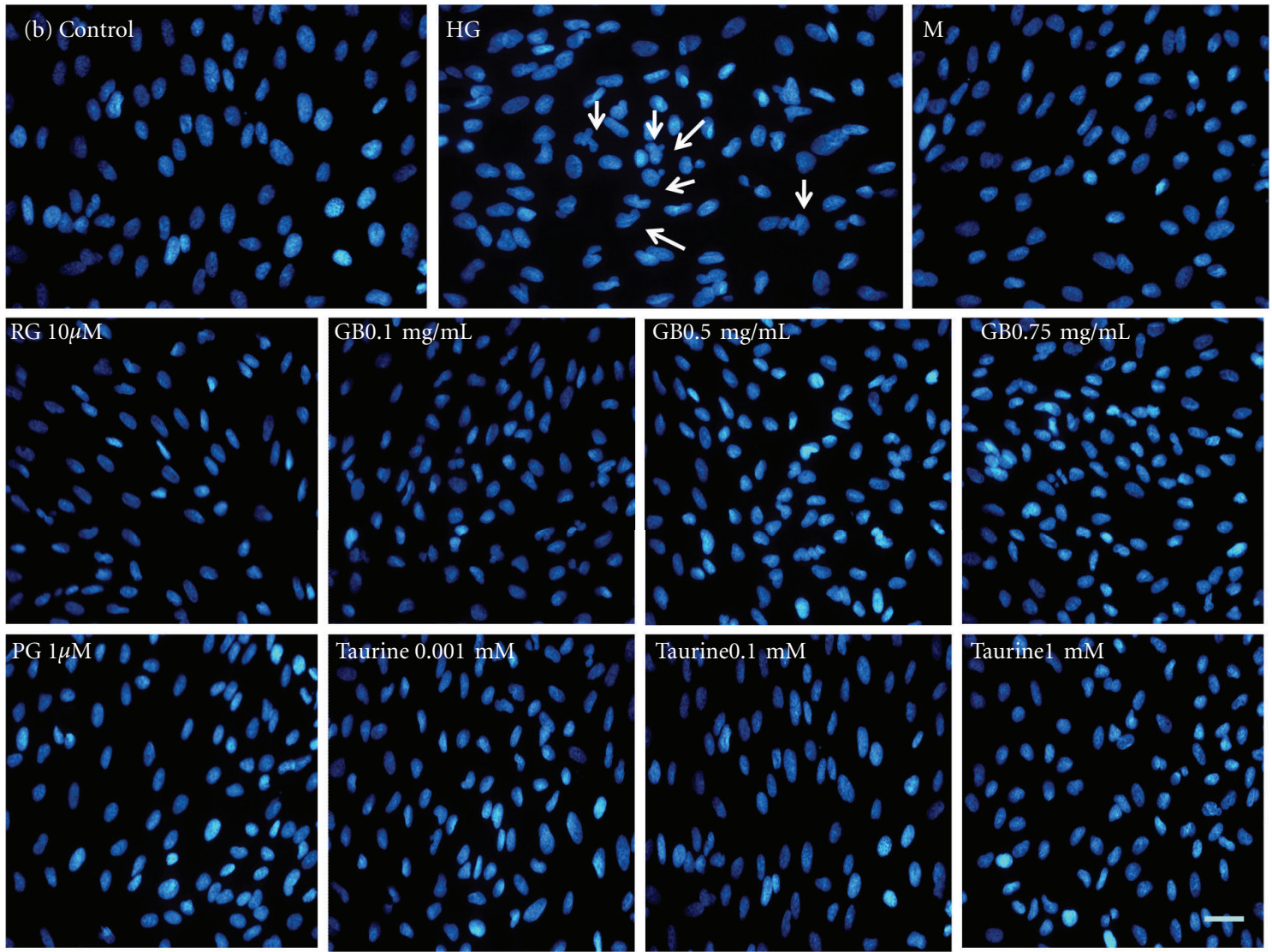

(b)

FIGURE 3: Effect of LB extract and taurine on high-glucose-induced ARPE-19 cells, with condensed and/or fragmented chromatin determined by the fluorescent dye Hoechst 33342 method. (a) Quantification of apoptotic cells in control and in high-glucose-induced ARPE- 19 cells treated in the absence and presence of LB extract $(0.1,0.5$, and $0.75 \mathrm{mg} / \mathrm{mL})$ or taurine $(0.001,0.1$, and $1 \mathrm{mM})$ for $48 \mathrm{~h}$. Positive controls (RG and PG) and the osmotic control (M) were also used. The results are presented as percentage of total number of cells counted (nonapoptotic + apoptotic) and represent the mean \pm SEM $\left(n=6\right.$ independent experiments). ${ }^{*} P<0.01$ versus HG; ${ }^{\#} P<0.05$ versus control. (b) Morphological analysis of control (panel 1) and high-glucose-treated ARPE-19 cells with Hoechst staining. Arrows indicate examples of cells with condensed and/or fragmented nuclei. Scale bar $50 \mu \mathrm{m}$. 
To further determine whether LB extract and taurine decreased apoptosis in high-glucose-induced ARPE-19 cells, apoptosis was measured as Annexin $\mathrm{V}$ binding to positive cells and quantified by flow cytometry, as Annexin V binds specifically to PS, allowing the discrimination between viable and apoptotic cells [38]. Representative dotplots of control and treated high-glucose-induced ARPE-19 cells stained with Annexin $\mathrm{V}$ and PI used for quantitation of apoptosis are shown in Figure 4(b). LB extract $(0.1,0.5$, and $0.75 \mathrm{mg} / \mathrm{mL}$ ) dose dependently decreased the number of Annexin V positive cells $(14.8,10.2$, and $6.4 \%$ of the control) (Figure 4(a)). Taurine dose dependently decreased the number of Annexin V-positive cells (14.8, 9.3, and 6.0\% of the control) (Figure 4(a)). The number of apoptotic cells in high-glucose culture was decreased by adding the positive controls, RG (by 10.0\%) and PG (6.1\%). The osmotic control did not enhance apoptotic cell death, excluding the involvement of osmotic effects of high-glucose concentrations.

\subsection{Effect of Taurine and LB Extract on Caspase-3 Pro-} tein Expression in High-Glucose-Treated ARPE-19 Cells. To explore the mechanisms of the anti-apoptotic effect of LB extract, protein levels of active caspase- 3 were examined by western blot analysis. LB extract $(0.1,0.5$, and $0.75 \mathrm{mg} / \mathrm{mL})$ dose dependently downregulated caspase- 3 protein expression (by 6.6-, 4.7-, and 2.7-fold, resp.) (Figure 5(a)).

Taurine $(0.001,0.1$, and $1 \mathrm{mM})$ dose dependently downregulated caspase-3 protein expression (by 7.0-, 5.2-, and 3.3fold, resp.) (Figure 5(b))

The protein levels of caspase- 3 in high-glucose-treated cells were decreased by adding the positive controls, RG (4.4fold) and PG (4.3-fold). The osmotic control did not enhance active caspase- 3 protein level, excluding the involvement of osmotic effects of high-glucose concentrations.

\subsection{Effect of Taurine and LB Extract on Caspase-3 Activity} in High-Glucose-Induced ARPE-19 Cells. To confirm the findings of the downregulating effect of LB extract and taurine on apoptosis, activated caspase- 3 in apoptotic cells was determined by fluorometric enzyme assay. LB extract $(0.1,0.5$, and $0.75 \mathrm{mg} / \mathrm{mL})$ dose dependently downregulated caspase-3 activity (by 5.0-, 4.2-, and 3.9-fold, resp.) (Figure 6).

Taurine $(0.001,0.1$, and $1 \mathrm{mM})$ dose dependently downregulated caspase-3 activity (by 5.7-, 4.2-, and 3.1-fold, resp.) (Figure 6).

The activated caspase- 3 levels in high-glucose condition were reversed by adding the positive controls, RG (2.8-fold) and PG (3.1-fold). The increased osmotic control did not enhance active caspase- 3 activity, excluding the involvement of osmotic effects of high-glucose concentrations.

\section{Discussion}

Diabetic retinopathy (DR) is a preventable microvascular diabetic complication, and hyperglycemia is considered a major factor in its development [39]. Although various hyperglycemia-induced metabolic abnormalities are implicated in DR [40], it has been difficult to pinpoint the exact pathogenic mechanism, thus making the rationale for a therapeutic target difficult. The results of numerous studies demonstrate that apoptosis is a critical part of the pathology of $\mathrm{DR}[4,6]$. Apoptotic cell death in retinal regions is a likely stimulus for the increased expression of molecules that enhance the breakdown of the blood retinal barrier (BRB) and lead to vascular proliferation [41]. Indeed, highglucose-induced apoptotic episodes have been demonstrated by retinal abnormalities, potential visual changes, and the onset of the first vascular change [42].

RPE is essential for neuroretina survival and, consequently, for visual function [43]. In response to damage caused by hyperglycemic condition, RPE cells migrate and proliferate, leading to a breakdown in adhesion between the RPE and the choroidal capillaries, followed by BRB breakdown, compromising blood flow within the RPE layer and leading to eventual retinal edema [37]. In addition, studies have shown that abnormalities in both the structural and secretory functions of RPE cells, followed by photoreceptor apoptosis are found in DR [43, 44].

An objective of the current study was to examine an extract of Goji berry and its major active component on protection of retinal epithelial cell against glucose-induced cytotoxicity as a model of diabetic retinopathy. Diabetes results in various metabolic and biochemical abnormalities in the retina, including increased oxidative stress, which has been shown to induce the expression of the proapoptotic molecules leading to apoptosis. Distinct members of the caspase family are involved in both the initiation and execution phases of apoptosis [45]. Among them, caspase-3 is the "executioner" caspase known to play an important role in the proteolytic cascade during apoptosis [46]. Moreover, the detection of activated caspase- 3 is a very reliable tool to identify cells destined to die by apoptosis [47].

Our previous work has established that Gogi berry and its taurine component activate PPAR- $\gamma$ [29]. PPAR$\gamma$ is heterogeneously expressed in the mammalian eye, prominently present in the retinal pigmented epithelium, photoreceptor outer segments, and choriocapillaris [48]. A recent study has shown that retinal expression of PPAR- $\gamma$ was suppressed in experimental models of diabetes and in endothelial cells treated with high glucose [49]. Moreover, recent studies have suggested that PPAR- $\gamma$ ligands, including $15 \mathrm{~d}_{-} \mathrm{PGJ}_{2}(\mathrm{PG})$ and rosiglitazone (RG), control apoptosis, contributing to tissue protection $[50,51]$. Moreover, a screen of FDA-approved compounds identified RG as a novel antiapoptotic agent in retinal cells both in vivo and in vitro [52]. Indeed, one recent study has shown that RG protects oxidative stress-induced apoptosis through upregulation of Bcl-2 and modulation of caspase-3 activation [17].

We have investigated the potential of Lycium barbarum (LB) as a natural medicine for management of diabetic retinopathy. $\mathrm{LB}$ is a traditional Chinese medicine used for centuries in the east and is believed to be beneficial for eye-related pathology [53]. Different biological activities of LB have been demonstrated, including antiaging and cytoprotection [54]. A recent study has shown that the 


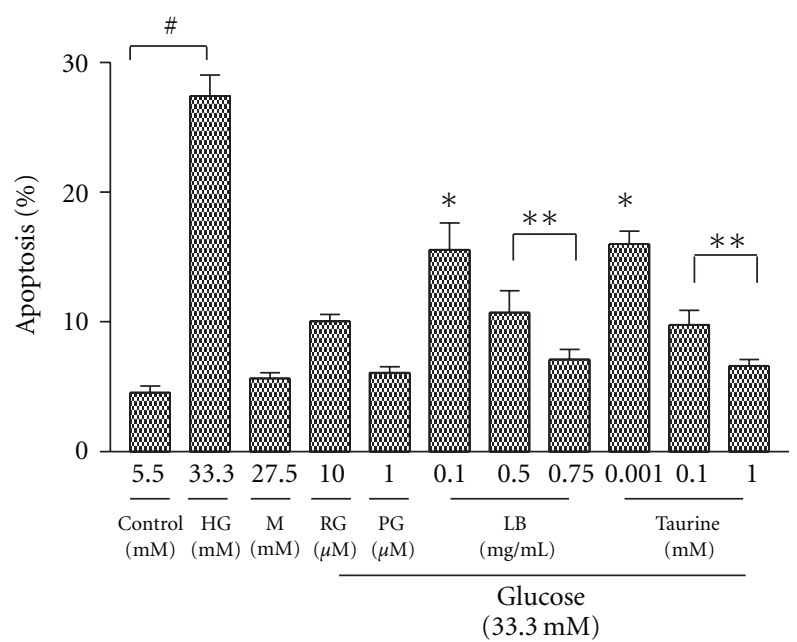

(a)
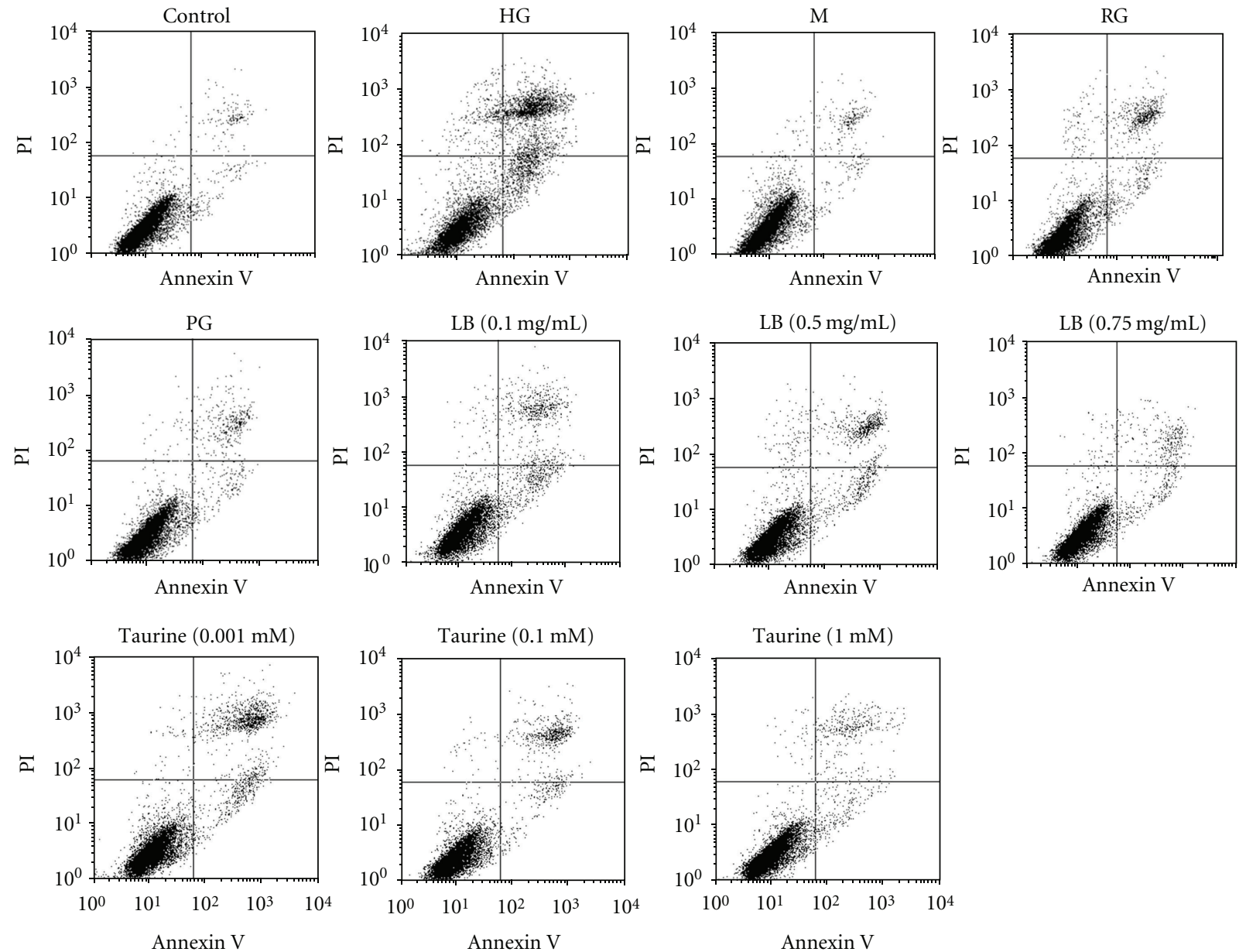

(b)

FIGURE 4: Effect of LB extract and taurine on high-glucose-induced apoptosis of ARPE-19 cells. Cells treated with LB extract (0.1, 0.5, and $0.75 \mathrm{mg} / \mathrm{mL})$ or taurine $(0.001,0.1$, and $1 \mathrm{mM})$ were exposed to high glucose $(33.3 \mathrm{mM})$ for $48 \mathrm{~h}$. (a) Quantification of apoptotic cells (Annexin V-positive) was determined by Annexin V/PI staining detected by flow cytometry. Results are expressed as percentages of Annexin $\mathrm{V}$ positive cells compared to control and presented as mean \pm SEM $\left(n=6\right.$ independent experiments). ${ }^{*} P<0.01$ versus HG; ${ }^{* *} P<0.001$ versus HG; ${ }^{\#} P<0.001$ versus control. (b) Representative dotplots of control and high-glucose-treated ARPE-19 cells stained with Annexin $\mathrm{V}$ and PI. 


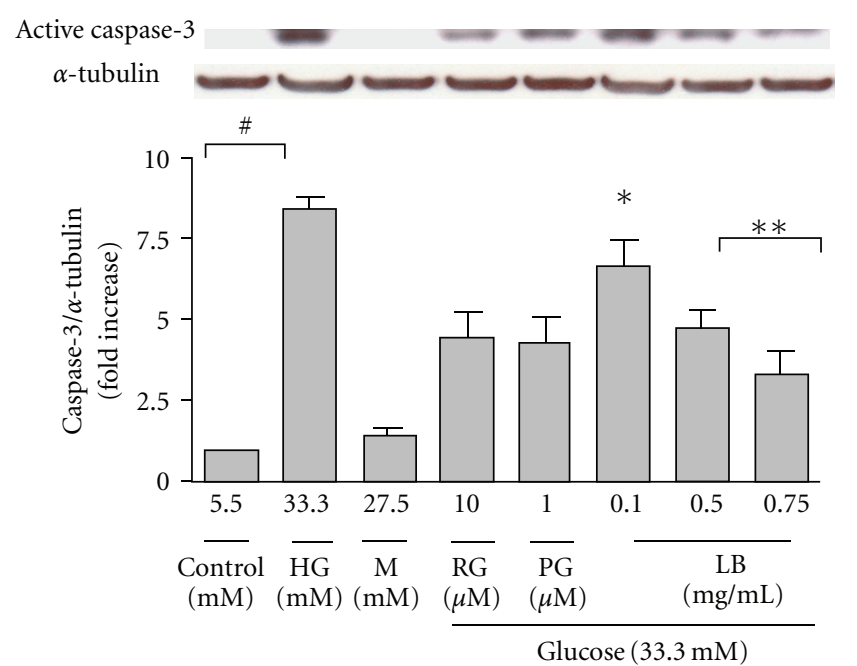

(a)

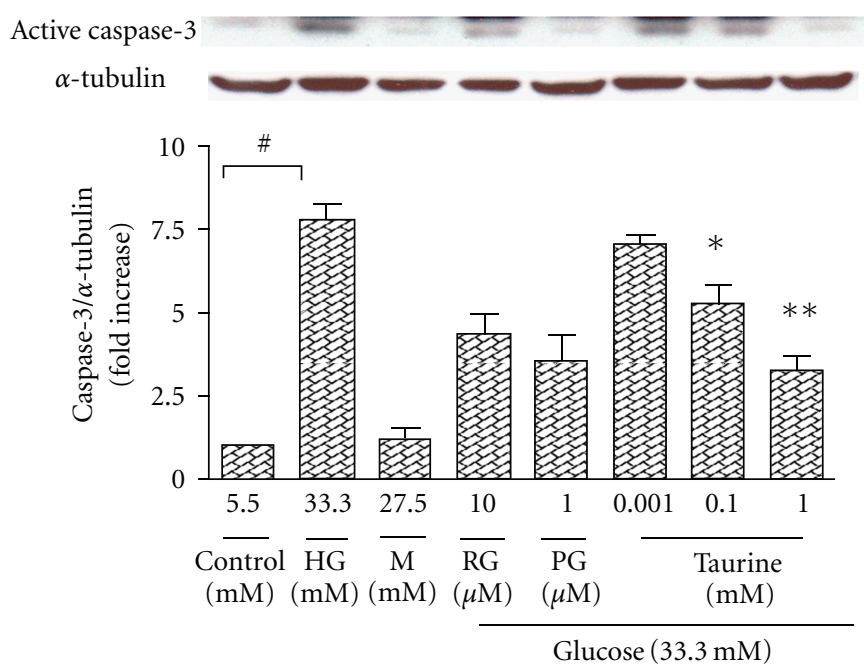

(b)

FIGURE 5: Effects of LB extract (a) and taurine (b) on protein expression of active caspase-3 in high-glucose-treated ARPE-19 cells. The relative level of protein encoding for active caspase-3 was assessed by western blot. Results were normalised to $\alpha$-tubulin. Levels in the control were arbitrarily assigned a value of 1.0. All values are means \pm SEM ( $n=5$ independent experiments). ${ }^{\#} P<0.001$ versus control, ${ }^{*} P<0.05,{ }^{* *} P<0.001$ versus $\mathrm{HG}$.

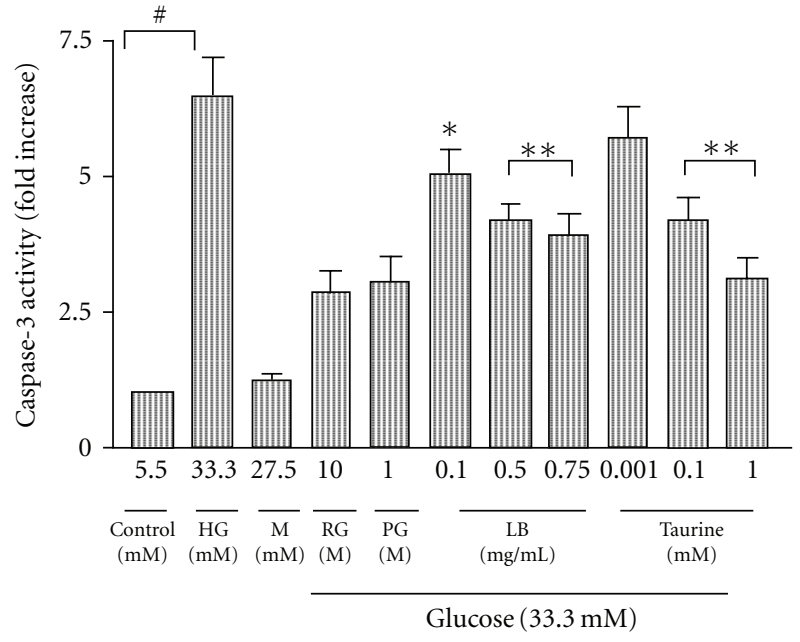

Figure 6: Caspase-3 activity in high-glucose-treated ARPE-19 cells. The effect of LB extract and taurine on fluorometrically determined caspase- 3 activity was measured in lysates of high-glucose-treated ARPE-19 cells. The $y$-axis shows the amount of free 7 -amino4-methylcoumarin (AMC) released from the caspase-3-specific substrate DEVD ( $N$-acetyl-Asp-Glu-Val-Asp)-AMC. Levels in the control were arbitrarily assigned a value of 1.0. All values are means \pm SEM $\left(n=4\right.$, each in duplicate). ${ }^{\#} P<0.001$ versus control, ${ }^{*} P<0.01, * * P<0.001$ versus $\mathrm{HG}$.

aqueous extract of LB exhibits neuroprotective effects against $\beta$-amyloid peptide-induced apoptosis in cultured neurons by attenuating the caspase-3-like activity [55]. Moreover, it has been suggested that LB polysaccharides (LBPs) effectively protected the retina from neuronal death and apoptosis by inhibiting proapoptotic signaling pathways, such as cJun N-terminal protein kinase (JNK), dsRNA-dependent protein kinase (PKR), and caspase-3 activity in retinal ischemia/reperfusion injury, confirming a neuroprotective role in ocular diseases [56]. In addition, the study showed anti-apoptotic activity of LBP in cultured seminiferous epithelium against hyperthermia-induced damage through the inhibition of superoxide-induced cyt c [57].

In parallel with the studies on LB extract, we have investigated the effect of taurine on apoptotic cytotoxicity pathways in ARPE-19 cells. Taurine is one of the major components in LB present in retina in abundance, where it is essential for sustaining retinal structure and function [25]. Various studies have shown that plasma and tissue levels of taurine are reduced in diabetes [58-60]. Indeed, studies have shown the beneficial effect of taurine supplementation in preventing or ameliorating hyperglycemiainduced retinal defects $[58,59]$. Moreover, recent studies have shown that diabetes or high-glucose-induced retinal glial cell apoptosis is inhibited by taurine, exhibiting effective prevention against DR [61]. Anti-apoptotic action of taurine has also been shown to occur by suppressing the $\mathrm{Ca}^{2+}$ dependent mitochondrial permeability transition ( $\mathrm{mPT}$ ) to prevent mitochondrial dysfunction and block activation of the cyt c/caspase-3 apoptotic pathway in rat retinal ganglion cells [62]. In addition, taurine exerts neuroprotective effects through an anti-apoptotic effect by increasing Bcl-2 levels, with a decrease in Bax and caspase-3 levels [15].

In previous work which formed the background leading to the present studies, we determined that LB extract and pure taurine, a major component in the LB extract, activated PPAR $-\gamma$ by luciferase reporter gene analysis and by mRNA and western blotting measurement in human retinal pigment epithelial cells. At the same time, both LB extract and pure taurine inhibited a variety of PPAR- $\gamma$-dependent downstream effectors in the retinal cells [29]. In the present 
study, we hypothesised that taurine and the LB extract may have a modulating effect on high-glucose-induced apoptosis through PPAR- $\gamma$-mediated caspase- 3 pathway, responsible for their effects in DR. In order to test this hypothesis, we first investigated the effect of taurine and LB extract on modulating cell viability and therefore apoptosis in highglucose-treated ARPE-19 cells. Our results demonstrated that a methanol extract of LB dose dependently overcame the decreased cell viability in high-glucose-treated ARPE-19 cells (Figure 2). Taurine had a similar effect on overcoming decreased cell viability (Figure 2). The cytoprotective effect of taurine was associated with the attenuation of high-glucoseinduced apoptosis, which was shown by characteristic morphological staining (Figure 3(b)) and Annexin V/PI double staining (Figure 4(b)), and a dose dependent decrease in the number of apoptotic cells (Figures 3(a) and 4(a)). Moreover, the results have shown that taurine and the LB extract dosedependently downregulated caspase- 3 protein expression (Figures 5(a) and 5(b)) and inhibited the enzymatic activity of caspase-3 (Figure 6). Therefore, the cytoprotective effect of LB extract parallels the profound suppression of highglucose-induced apoptosis at the site of caspase-3 regulation. The effects of taurine closely mimicked the effects of the methanolic LB extract, since they occurred at concentrations $0.001-1.00 \mathrm{mM}$ which we showed previously [29] were present in the range of methanolic extract used in the treatments $(0.1$ to $0.75 \mathrm{mg} / \mathrm{mL})$. However, we cannot exclude the possibility that other components may also contribute to the cytoprotective effects of LB.

In summary, this study has demonstrated for the first time that the traditional Chinese medicine Lycium barbarum is cytoprotective against high-glucose cytotoxicity in retinal pigment epithelial cells, at least in part by regulating apoptosis as a result of caspase-3 modulation. This may occur through the initial PPAR- $\gamma$ activation found in previous studies [29]. The effects of the extract are closely mimicked by taurine at concentrations present in the extracts. This pathway and demonstration of its major active component provide a rationale for the therapeutic use of taurine and the valuable medicinal herb LB for the prevention of DR. However, further investigation into their specific mechanisms is warranted to gather proof of efficacy and safety of taurine and LB for protection against DR in various preclinical and clinical settings.

\section{Acknowledgments}

The authors thank Benjamin Kimble (Faculty of Veterinary Science, The University of Sydney, Australia) for suggestions and technical instructions in the phytochemical analysis; the National Institute of Complementary Medicine (NICM) and the Pharmacy Faculty for a postgraduate scholarship (MKS) and funding support to BDR.

\section{References}

[1] D. S. Fong, L. P. Aiello, F. L. Ferris, and R. Klein, "Diabetic retinopathy," Diabetes Care, vol. 27, no. 10, pp. 2540-2553, 2004.
[2] A. Decanini, P. R. Karunadharma, C. L. Nordgaard, X. Feng, T. W. Olsen, and D. A. Ferrington, "Human retinal pigment epithelium proteome changes in early diabetes," Diabetologia, vol. 51, no. 6, pp. 1051-1061, 2008.

[3] J. C. S. Yam and A. K. H. Kwok, "Update on the treatment of diabetic retinopathy," Hong Kong Medical Journal, vol. 13, no. 1, pp. 46-60, 2007.

[4] E. C. Leal, C. A. Aveleira, A. F. Castilho et al., "High glucose and oxidative/nitrosative stress conditions induce apoptosis in retinal endothelial cells by a caspase-independent pathway," Experimental Eye Research, vol. 88, no. 5, pp. 983-991, 2009.

[5] R. A. Kowluru and S. Odenbach, "Effect of long-term administration of $\alpha$-lipoic acid on retinal capillary cell death and the development of retinopathy in diabetic rats," Diabetes, vol. 53, no. 12, pp. 3233-3238, 2004.

[6] A. J. Barber, T. W. Gardner, and S. F. Abcouwer, "The significance of vascular and neural apoptosis to the pathology of diabetic retinopathy," Investigative Ophthalmology and Visual Science, vol. 52, no. 2, pp. 1156-1163, 2011.

[7] M. K. Song, B. D. Roufogalis, and T. H.W. Huang, "Modulation of diabetic retinopathy pathophysiology by natural medicines through PPAR- $\gamma$-related pharmacology," British Journal of Pharmacology, vol. 165, no. 1, pp. 4-19, 2012.

[8] L. J. Rizzolo, "Polarity and the development of the outer blood-retinal barrier," Histology and Histopathology, vol. 12, no. 4, pp. 1057-1067, 1997.

[9] S. Beatty, H. H. Koh, M. Phil, D. Henson, and M. Boulton, "The role of oxidative stress in the pathogenesis of age-related macular degeneration," Survey of Ophthalmology, vol. 45, no. 2, pp. 115-134, 2000.

[10] R. Roduit and D. F. Schorderet, "MAP kinase pathways in UV-induced apoptosis of retinal pigment epithelium ARPE19 cells," Apoptosis, vol. 13, no. 3, pp. 343-353, 2008.

[11] J. H. Kim, J. H. Kim, H. O. Jun et al., "Protective effect of clusterin from oxidative stress-induced apoptosis in human retinal pigment epithelial cells," Investigative Ophthalmology \& Visual Science, vol. 51, no. 1, pp. 561-566, 2010.

[12] Y. Yanagi, "Role of peoxisome proliferator activator receptor $\gamma$ on blood retinal barrier breakdown," PPAR Research, Article ID 679237, 2008.

[13] S. T. Knudsen, T. Bek, P. L. Poulsen, M. N. Hove, M. Rehling, and C. E. Mogensen, "Macular edema reflects generalized vascular hyperpermeability in type 2 diabetic patients with retinopathy," Diabetes Care, vol. 25, no. 12, pp. 2328-2334, 2002.

[14] D. A. Allen, M. M. Yaqoob, and S. M. Harwood, "Mechanisms of high glucose-induced apoptosis and its relationship to diabetic complications," Journal of Nutritional Biochemistry, vol. 16, no. 12, pp. 705-713, 2005.

[15] J. Jeong, T. Kim, H. Park et al., "Taurine exerts neuroprotective effects via anti-apoptosis in hypoxic-ischemic brain injury in neonatal rats," Korean Journal of Pediatrics, vol. 52, no. 12, pp. 1337-1347, 2009.

[16] T. S. Kern, J. Tang, M. Mizutani et al., "Response of capillary cell death to aminoguanidine predicts the development of retinopathy: comparison of diabetes and galactosemia," Investigative Ophthalmology and Visual Science, vol. 41, no. 12, pp. 3972-3978, 2000.

[17] J. S. Wu, T. N. Lin, and K. K. Wu, "Rosiglitazone and PPAR$\gamma$ overexpression protect mitochondrial membrane potential and prevent apoptosis by upregulating anti-apoptotic Bcl-2 family proteins," Journal of Cellular Physiology, vol. 220, no. 1, pp. 58-71, 2009. 
[18] Y. Ren, C. Sun, Y. Sun et al., "PPAR $\gamma$ protects cardiomyocytes against oxidative stress and apoptosis via Bcl-2 upregulation," Vascular Pharmacology, vol. 51, no. 2-3, pp. 169-174, 2009.

[19] G. A. Rodrigues, F. Maurier-Mahe, D.-L. Shurland et al., "Differential effects of PPAR $\gamma$ ligands on oxidative stressinduced death of retinal pigmented epithelial cells," Investigative Ophthalmology and Visual Science, vol. 52, no. 2, pp. 890903, 2011.

[20] J. Y. Chang, P. S. Bora, and N. S. Bora, "Prevention of oxidative stress-induced retinal pigment epithelial cell death by the PPAR $\gamma$ agonists, 15-deoxy-delta 12, 14-prostaglandin J 2," PPAR Research, Article ID 720163, 2008.

[21] H. Zhao, A. Alexeev, E. Chang, G. Greenburg, and K. Bojanowski, "Lycium barbarum glycoconjugates: effect on human skin and cultured dermal fibroblasts," Phytomedicine, vol. 12, no. 1-2, pp. 131-137, 2005.

[22] C. Y. Cheng, W. Y. Chung, Y. T. Szeto, and I. F. F. Benzie, "Fasting plasma zeaxanthin response to Fructus barbarum L. (wolfberry; Kei Tze) in a food-based human supplementation trial," British Journal of Nutrition, vol. 93, no. 1, pp. 123-130, 2005.

[23] Q. Wang, "The present situation of TCM treatment for diabetes and its researches," Journal of Traditional Chinese Medicine, vol. 23, no. 1, pp. 67-73, 2003.

[24] H. Xie and S. Zhang, "Determination of taurine in Lycium barbarum L. by high performance liquid chromatography with OPA-urea pre-column derivatization," Se Pu, vol. 15, no. 1, pp. 54-56, 1997.

[25] Y. Cao, X. Zhang, Q. Chu, Y. Fang, and J. Ye, "Determination of taurine in Lycium barbarum L. and other foods by capillary electrophoresis with electrochemical detection," Electroanalysis, vol. 15, no. 10, pp. 898-902, 2003.

[26] X. Yu, Z. Xu, M. Mi et al., "Dietary taurine supplementation ameliorates diabetic retinopathy via anti-excitotoxicity of glutamate in streptozotocin-induced sprague-dawley rats," Neurochemical Research, vol. 33, no. 3, pp. 500-507, 2008.

[27] T. Takatani, K. Takahashi, Y. Uozumi et al., "Taurine prevents the ischemia-induced apoptosis in cultured neonatal rat cardiomyocytes through Akt/caspase-9 pathway," Biochemical and Biophysical Research Communications, vol. 316, no. 2, pp. 484-489, 2004.

[28] Q. Di Wu, J. H. Wang, F. Fennessy, H. P. Redmond, and D. Bouchier-Hayes, "Taurine prevents high-glucose-induced human vascular endothelial cell apoptosis," American Journal of Physiology, vol. 277, no. 6, pp. C1229-C1238, 1999.

[29] M. K. Song, N. K. Salam, B. D. Roufogalis, and T. H. W. Huang, "Lycium barbarum (Goji Berry) extracts and its taurine component inhibit PPAR- $\gamma$-dependent gene transcription in human retinal pigment epithelial cells: possible implications for diabetic retinopathy treatment," Biochemical Pharmacology, vol. 82, no. 9, pp. 1209-1218, 2011.

[30] M. Ganzera, J. Zhao, and I. A. Khan, "Analysis of terpenelactones in Ginkgo biloba by high performance liquid chromatography and evaporative light scattering detection," Chemical and Pharmaceutical Bulletin, vol. 49, no. 9, pp. 1170$1173,2001$.

[31] K. C. Dunn, A. E. Aotaki-Keen, F. R. Putkey, and L. M. Hjelmeland, "ARPE-19, a human retinal pigment epithelial cell line with differentiated properties," Experimental Eye Research, vol. 62, no. 2, pp. 155-169, 1996.

[32] T. Yokoyama, K. Yamane, A. Minamoto et al., "High glucose concentration induces elevated expression of anti-oxidant and proteolytic enzymes in cultured human retinal pigment epithelial cells," Experimental Eye Research, vol. 83, no. 3, pp. 602-609, 2006.
[33] H. S. Chung, M. Kang, C. Cho et al., "Inhibition of nitric oxide and tumor necrosis factor- $\alpha$ by moutan cortex in activated mouse peritoneal macrophages," Biological and Pharmaceutical Bulletin, vol. 30, no. 5, pp. 912-916, 2007.

[34] P. M. K. Tang, J. Y. W. Chan, S. W. N. Au et al., "Pheophorbide a, an active compound isolated from Scutellaria barbata, possesses photodynamic activities by inducing apoptosis in human hepatocellular carcinoma," Cancer Biology and Therapy, vol. 5, no. 9, pp. 1111-1116, 2006.

[35] H. T. Hassoun, M. L. Lie, D. N. Grigoryev, M. Liu, R. M. Tuder, and H. Rabb, "Kidney ischemia-reperfusion injury induces caspase-dependent pulmonary apoptosis," American Journal of Physiology, vol. 297, no. 1, pp. F125-F137, 2009.

[36] G. F. Davies, P. J. Mcfie, R. L. Khandelwal, and W. J. Roesler, "Unique ability of troglitazone to up-regulate peroxisome proliferator-activated receptor- $\gamma$ expression in hepatocytes," Journal of Pharmacology and Experimental Therapeutics, vol. 300, no. 1, pp. 72-77, 2002.

[37] C. J. Kennedy, P. E. Rakoczy, and I. J. Constable, "Lipofuscin of the retinal pigment epithelium: a review," Eye, vol. 9, no. 6, pp. 763-771, 1995.

[38] I. Vermes, C. Haanen, and C. Reutelingsperger, "Flow cytometry of apoptotic cell death," Journal of Immunological Methods, vol. 243, no. 1-2, pp. 167-190, 2000.

[39] T. K. Ali and A. B. El-Remessy, "Diabetic retinopathy: current management and experimental therapeutic targets," Pharmacotherapy, vol. 29, no. 2, pp. 182-192, 2009.

[40] R. A. Kowluru, L. Atasi, and Y. S. Ho, "Role of mitochondrial superoxide dismutase in the development of diabetic retinopathy," Investigative Ophthalmology and Visual Science, vol. 47, no. 4, pp. 1594-1599, 2006.

[41] A. Patz, "Clinical and experimental studies on retinal neovascularization. XXXIX Edward Jackson memorial lecture," American Journal of Ophthalmology, vol. 94, no. 6, pp. 715$743,1982$.

[42] R. A. Kowluru, "Diabetic retinopathy: mitochondrial dysfunction and retinal capillary cell death," Antioxidants and Redox Signaling, vol. 7, no. 11-12, pp. 1581-1587, 2005.

[43] R. Simo, M. Villarroel, L. Corraliza, C. Hernandez, and M. Garcia-Ramirez, "The retinal pigment epithelium: something more than a constituent of the blood-retinal barrierimplications for the pathogenesis of diabetic retinopathy," Journal of Biomedicine \& Biotechnology, vol. 2010, Article ID 190724, 15 pages, 2010.

[44] Y. Aizu, K. Oyanagi, J. Hu, and H. Nakagawa, "Degeneration of retinal neuronal processes and pigment epithelium in the early stage of the streptozotocin-diabetic rats," Neuropathology, vol. 22, no. 3, pp. 161-170, 2002.

[45] A. M. Abu El-Asrar, L. Dralands, L. Missotten, I. A. Al-Jadaan, and K. Geboes, "Expression of apoptosis markers in the retinas of human subjects with diabetes," Investigative Ophthalmology and Visual Science, vol. 45, no. 8, pp. 2760-2766, 2004.

[46] W. C. Earnshaw, L. M. Martins, and S. H. Kaufmann, "Mammalian caspases: structure, activation, substrates, and functions during apoptosis," Annual Review of Biochemistry, vol. 68, pp. 383-424, 1999.

[47] C. Stadelmann and H. Lassmann, "Detection of apoptosis in tissue sections," Cell and Tissue Research, vol. 301, no. 1, pp. 19-31, 2000.

[48] A. A. Herzlich, J. Tuo, and C. C. Chan, "Peroxisome proliferator-activated receptor and age-related macular degeneration," PPAR Research, vol. 2008, Article ID 389507, 11 pages, 2008. 
[49] A. Tawfik, T. Sanders, K. Kahook, S. Akeel, A. Elmarakby, and M. Al-Shabrawey, "Suppression of retinal peroxisome proliferator-activated receptor $\gamma$ in experimental diabetes and oxygen-induced retinopathy: role of NADPH oxidase," Investigative Ophthalmology and Visual Science, vol. 50, no. 2, pp. 878-884, 2009.

[50] T. N. Lin, W. M. Cheung, J. S. Wu et al., "15d-prostaglandin J2 protects brain from ischemia-reperfusion injury," Arteriosclerosis, Thrombosis, and Vascular Biology, vol. 26, no. 3, pp. 481$487,2006$.

[51] K. Fuenzalida, R. Quintanilla, P. Ramos et al., "Peroxisome proliferator-activated receptor $\gamma$ up-regulates the $\mathrm{Bcl}-2$ antiapoptotic protein in neurons and induces mitochondrial stabilization and protection against oxidative stress and apoptosis," Journal of Biological Chemistry, vol. 282, no. 51, pp. 3700637015, 2007.

[52] F. Doonan, D. M. Wallace, C. O’Driscoll, and T. G. Cotter, "Rosiglitazone acts as a neuroprotectant in retinal cells via upregulation of sestrin-1 and SOD-2," Journal of Neurochemistry, vol. 109, no. 2, pp. 631-643, 2009.

[53] R. C. C. Chang and K. F. So, "Use of anti-aging herbal medicine, Lycium barbarum, against aging-associated diseases. What do we know so far?" Cellular and Molecular Neurobiology, vol. 28, no. 5, pp. 643-652, 2008.

[54] X. M. Li, Y. L. Ma, and X. J. Liu, "Effect of the Lycium barbarum polysaccharides on age-related oxidative stress in aged mice," Journal of Ethnopharmacology, vol. 111, no. 3, pp. 504-511, 2007.

[55] M. S. Yu, S. K. Y. Leung, S. W. Lai et al., "Neuroprotective effects of anti-aging oriental medicine Lycium barbarum against $\beta$-amyloid peptide neurotoxicity," Experimental Gerontology, vol. 40, no. 8-9, pp. 716-727, 2005.

[56] S.-Y. Li, D. Yang, C.-M. Yeung et al., "Lycium barbarum polysaccharides reduce neuronal damage, bloodretinal barrier disruption and oxidative stress in retinal ischemia/reperfusion injury," PLoS ONE, vol. 6, no. 1, p. e16380, 2011.

[57] Y. Wang, H. Zhao, X. Sheng, P. E. Gambino, B. Costello, and K. Bojanowski, "Protective effect of Fructus Lycii polysaccharides against time and hyperthermia-induced damage in cultured seminiferous epithelium," Journal of Ethnopharmacology, vol. 82, no. 2-3, pp. 169-175, 2002.

[58] S. H. Hansen, "The role of taurine in diabetes and the development of diabetic complications," Diabetes/Metabolism Research and Reviews, vol. 17, no. 5, pp. 330-346, 2001.

[59] F. Franconi, A. Loizzo, G. Ghirlanda, and G. Seghieri, “Taurine supplementation and diabetes mellitus," Current Opinion in Clinical Nutrition and Metabolic Care, vol. 9, no. 1, pp. 32-36, 2006.

[60] F. Franconi, M. A. S. Di Leo, F. Bennardini, and G. Ghirlanda, "Is taurine beneficial in reducing risk factors for diabetes mellitus?" Neurochemical Research, vol. 29, no. 1, pp. 143-150, 2004.

[61] K. Zeng, H. Xu, M. Mi et al., "Effects of taurine on glial cells apoptosis and taurine transporter expression in retina under diabetic conditions," Neurochemical Research, vol. 35, no. 10, pp. 1566-1574, 2010.

[62] K. Chen, Q. Zhang, J. Wang et al., "Taurine protects transformed rat retinal ganglion cells from hypoxia-induced apoptosis by preventing mitochondrial dysfunction," Brain Research, vol. 1279, pp. 131-138, 2009. 


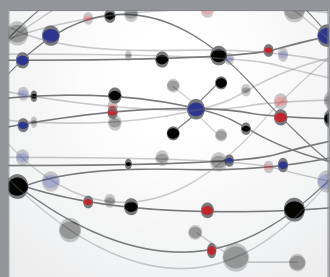

The Scientific World Journal
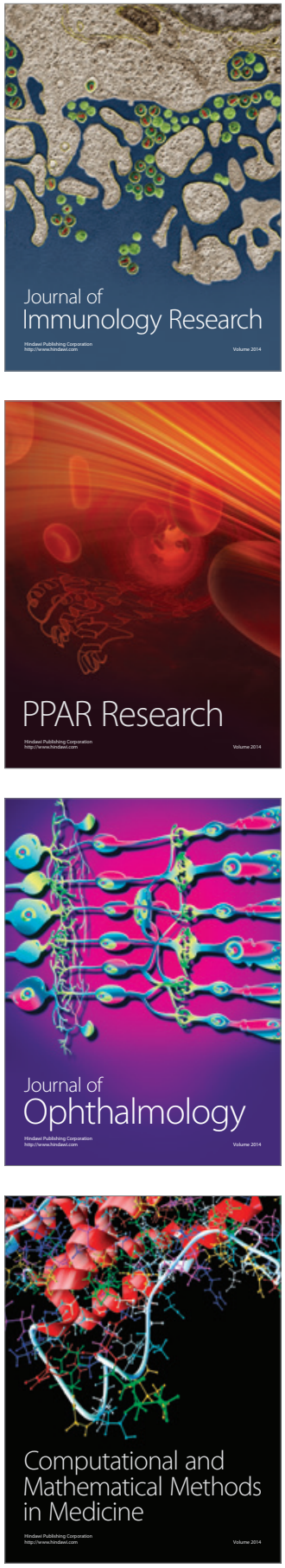

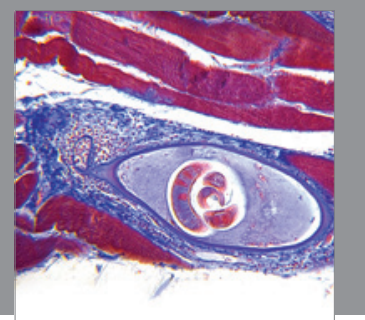

Gastroenterology

Research and Practice
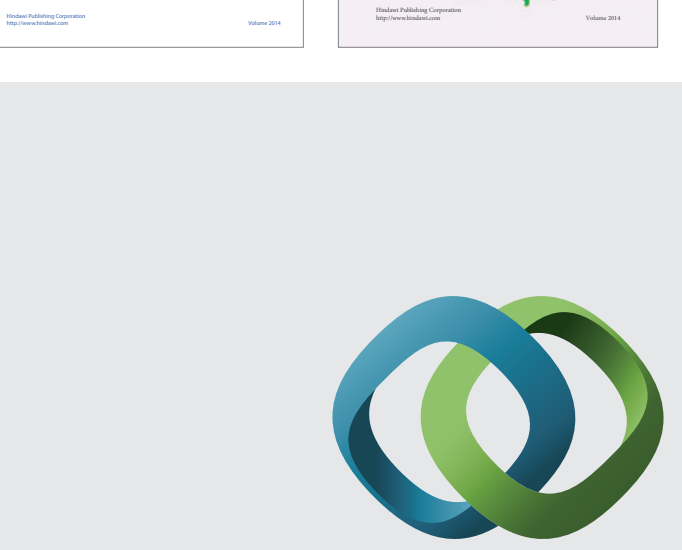

\section{Hindawi}

Submit your manuscripts at

http://www.hindawi.com
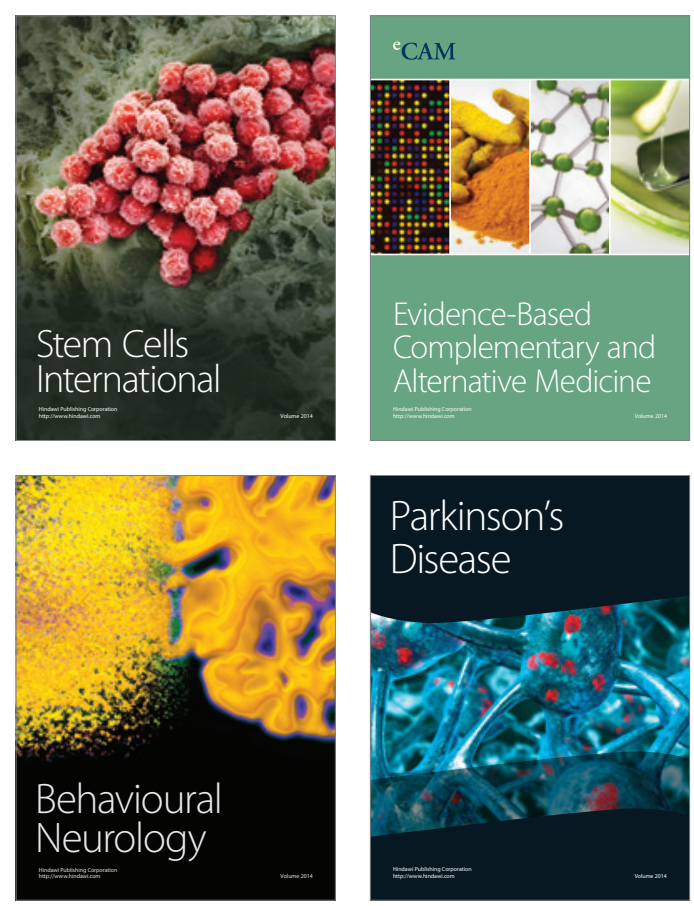

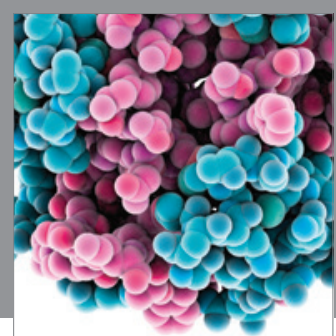

Journal of
Diabetes Research

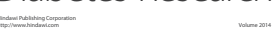

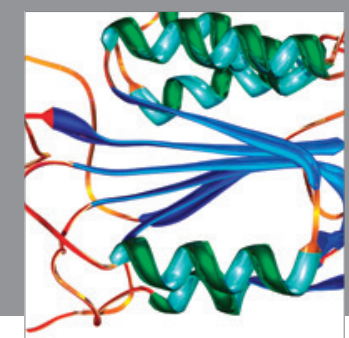

Disease Markers
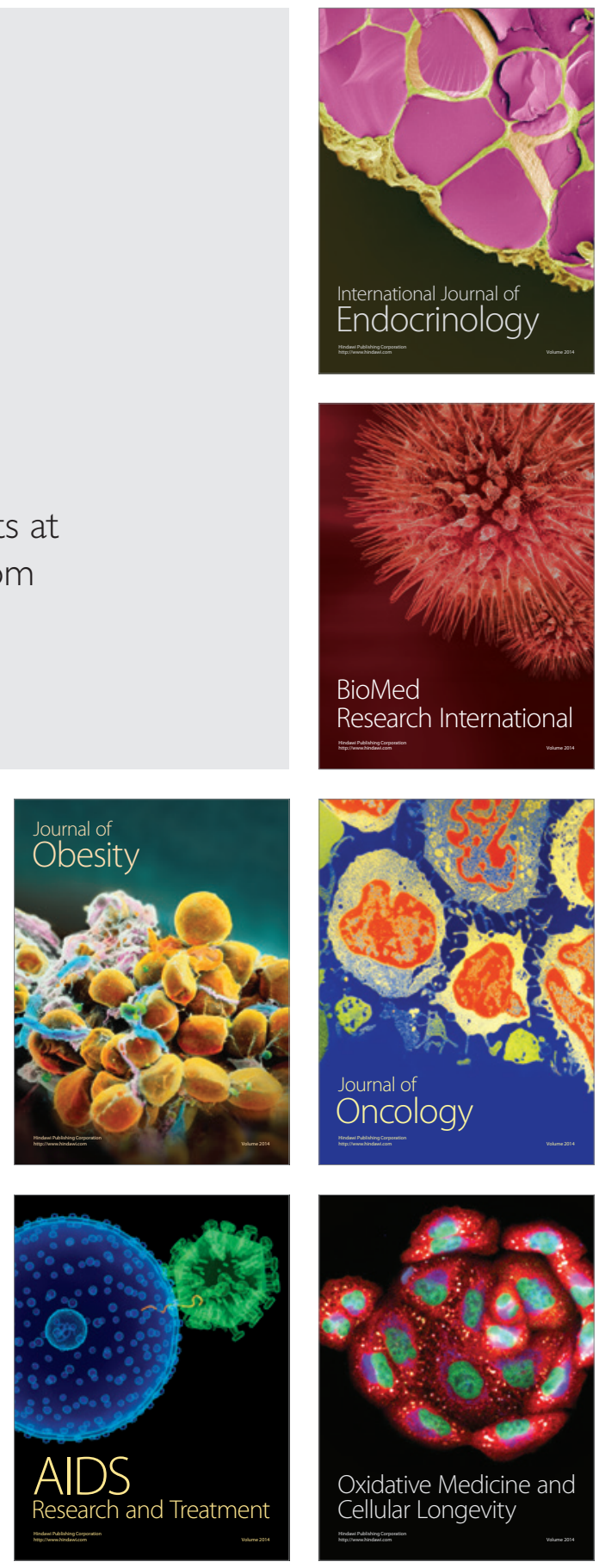